\title{
LIVRO DIDÁTICO DE LÍNGUA PORTUGUESA: UM GÊNERO DE DISCURSO MULTIMODAL
}

\author{
PORTUGUESA LANGUAGE TEXTBOOK: A GENRE OF \\ MULTIMODAL DISCURSE
}

\author{
Sandro Luis Silva* \\ Juliana Souza Lopes Hott da Rocha**
}

\begin{abstract}
Resumo: Há muito vem se discutindo a importância do livro didático no processo de ensinoaprendizagem. Neste artigo, trazemos algumas reflexões sobre a interface entre livro didático, gênero de discurso e multimodalidade. Procuramos observar em que medida o livro didático é caracterizado como um gênero de discurso multimodal, uma vez que apresenta uma simbiose de linguagens. Para atingir nosso objetivo, recorremos aos pressupostos enunciativo-discursivos de abordagem sócio-histórica Bakhtin (2011), aliados a fundamentos da multimodalidade, apresentados por Rojo e Barbosa (2015), Dionísio (2013), Bonini (2011) e Maingueneau (2016). Apresentamos como corpus dois livros didáticos do ensino fundamental, o que nos revelou a presença de elementos que fazem com que o livro didático seja considerado um gênero de discurso multimodal, o qual abre perspectiva para o aluno se tornar um leitor crítico, se o livro didático for trabalhado no processo de ensino-aprendizagem como um gênero multimodal.
\end{abstract}

Palavras-chave: livro didático; gêneros discursivos; multimodalidade.

\begin{abstract}
The importance of textbooks in the teaching-learning process has long been discussed. In this article, we bring some reflections on the interface between textbook, discourse genre and multimodality. We try to observe to what extent the textbook is characterized as a genre of multimodal discourse, since it presents a symbiosis of languages. In order to achieve our objective, we have used the socio-historical and socio-historical assumptions Bakhtin (2011), allied to the foundations of multimodality, presented by Red and Barbosa (2015), Dionísio (2013), Bonini (2011) and Maingueneau . We present as corpus two textbooks of elementary school, which revealed the presence of elements that make the textbook be considered a genre of multimodal discourse, which opens the perspective for the student to become a critical reader, if the textbook in the teaching-learning process as a multimodal genre.
\end{abstract}

Keywords: textbook; discursive genres; multimodality.

\section{Palavras iniciais}

Da primeira metade do século XX até meados dos anos 1950, não havia a utilização de livros didáticos como os conhecemos no processo de ensino-aprendizagem por que passamos atualmente. Segundo Magda Soares (2002), os livros didáticos eram poucos; havia a dominância da utilização da Antologia Nacional, de Fasto Barreto e Carlos de Laerte, cujo conteúdo era constituído por apenas uma coletânea de textos. A escola, por sua vez, era tão-somente o espaço para o ensino da gramática normativa, sem exercícios ou atividades a partir dos quais o aluno pudesse perceber $o$ funcionamento da língua no cotidiano do sujeito que dela se vale para se comunicar.

A partir de meados dos anos 1950, os livros didáticos de língua portuguesa começam a adquirir novo formato, em decorrência de diversas circunstâncias. Dentre elas, podemos citar o fato de passarem a ser produzidos por professores especialistas da

\footnotetext{
* Universidade Federal de São Paulo. Mestre em Literatura Portuguesa pela Universidade de São Paulo. Doutor em Língua Portuguesa pela Pontifícia Universidade Católica de São Paulo. Professor Adjunto de Língua Portuguesa e Ensino na Universidade Federal de São Paulo. E-mail: sandro.luis2602@gmail.com ** Universidade Federal de São Paulo.Mestre em Letras pelo Programa de Pós-Graduação em Letras da Universidade Federal de São Paulo. E-mail: julianahott@gmail.com.
} 
área e, um pouco mais à frente, houve a publicação da Lei de Diretrizes e Bases (Lei n. 5.692/71), que promoveu uma reestruturação dos conteúdos da disciplina língua portuguesa, privilegiando, então, o ensino da língua(gem) e seu uso em diferentes contextos. Surge a necessidade de os autores de livros didáticos repensarem a composição desses materiais e incluírem textos em variadas linguagens, uma verdadeira transformação do conteúdo, configurando a presença da multimodalidade, ainda que não fosse usada esta nomenclatura e/ou esse conceito sistematizado.

De acordo com Bezerra (2003), inicialmente, apenas textos literários compunham os livros didáticos de língua portuguesa, reproduzindo uma ideia de que somente a produção literária era texto que deveria ser estudado na prática pedagógica. Com essas mudanças, os livros didáticos foram se estruturando à maneira que conhecemos hoje, ou seja, compostos por diversos gêneros - que perdem sua função primeira e passam a ser objeto de ensino, possibilitando o trabalho com vocabulário, interpretação, gramática, redação, além de outros elementos, como as ilustrações, que caracterizam o não-verbal. Diante dessa nova configuração do livro didático de língua portuguesa, surge a necessidade de entender como se dá sua constituição, a fim de entendê-lo como gênero de discurso.

Tendo em vista essas considerações preliminares, objetivamos analisar o livro didático de língua portuguesa como gênero de discurso multimodal, tendo em vista a simbiose de linguagem que o constitui. Nosso estudo pauta-se em Bakhtin (2011), Maingueneau (2006, 2010 e 2016), Bunzen (2005), Rojo e Barbosa (2015) e Bonini (2011), além de Kress ( 1996) e Dionísio (2005, 2011), quanto às questões relacionadas à multimodalidade. Para atingir o objetivo proposto, o artigo está dividido em duas grandes partes: na primeira, trazemos à baila reflexões sobre as questões teóricas relativas ao gênero de discurso e à multimodalidade, conceitos que sustentam a segunda parte do artigo, em que apresentamos a análise do corpus escolhido: dois livros didáticos do ensino fundamental II. Em seguida, apresentamos as considerações finais e as referências utilizadas.

\section{O gênero de discurso e multimodalidade: algumas reflexões}

O nosso entendimento a respeito de gêneros de discurso baseia-se, inicialmente, em Bakhtin (2011), que define gênero de discurso como tipos relativamente estáveis de enunciados. O autor mostra que os campos da atividade humana estão sempre ligados ao uso da linguagem, que se efetiva por meio de enunciados ${ }^{1}$ orais ou escritos; tais enunciados são únicos e refletem as condições específicas e as finalidades dos campos da atividade humana em que estão inseridos.

Bakhtin aponta três elementos constitutivos dos gêneros de discurso quando afirma que "todos esses três elementos - o conteúdo temático, o estilo, a construção composicional - estão indissoluvelmente ligados no todo do enunciado e são igualmente determinados pela especificidade de um determinado campo da comunicação" (BAKHTIN, 2011, p. 261). Tais elementos merecem especial atenção, uma vez que são eles que determinam a forma de composição de um enunciado enquanto gênero do discurso.

Para Bakhtin (2011), o estilo está indissoluvelmente ligado ao enunciado e às formas típicas de enunciados, a que chama gêneros de discurso. $\mathrm{O}$ autor aponta a

\footnotetext{
${ }^{1}$ Enunciado, neste artigo, entendido como "unidade real da comunicação discursiva" (Bakhtin, 2011, p. 269)
} 
individualidade desse estilo, que pode refletir a individualidade do falante; ele ressalta, ainda, que há gêneros de discurso que não são propícios ao reflexo dessa individualidade, ou seja, ao estilo individual, como nos gêneros que requerem uma forma mais padronizada, em que a própria unidade temática irá requerer um estilo próprio e indissociável a ela. Em suma, nas palavras do autor, "em cada campo existem e são empregados gêneros que correspondem às condições específicas de dado campo; é a esses gêneros que correspondem determinados estilos" (BAKHTIN, 2011, p. 266). O filósofo da linguagem russo expõe, ainda, que há uma heterogeneidade de gêneros de discurso e não há um plano único para o seu estudo; apresenta-nos uma diferenciação entre gêneros primários, que seriam os gêneros simples, produzidos espontaneamente no dia a dia, nas condições da comunicação discursiva imediata e os secundários que reelaboram e incorporam diversos gêneros primários, configurando-se, portanto, como mais complexos; estes surgem diante de condições de convívio mais organizadas e desenvolvidas, predominantemente escrita.

Maingueneau (2006), por sua vez, expõe que a categoria gênero de discurso é definida a partir de critérios situacionais. Para o autor francês, ela designa dispositivos de comunicação sócio-historicamente definidos e que, por sua natureza, os gêneros evoluem sem cessar par a par com a sociedade. $O$ autor estabelece uma distinção entre os gêneros conversacionais e os instituídos; os primeiros não possuem relação com lugares, papéis ou roteiros relativamente estáveis, uma vez que sua composição e sua temática são, em geral, bastante instáveis e seu quadro se transforma incessantemente. Já os instituídos reúnem o que Maingueneau chama de gêneros autorais (geridos pelo próprio autor e eventualmente por um editor) e gêneros rotineiros, que são os preferidos pelos analistas do discurso e os que melhor correspondem à definição de gênero de discurso como dispositivo de comunicação entendido sócio-historicamente. Tal distinção nos faz lembrar, de certo modo, a divisão feita por Bakhtin (2011) entre gêneros primários e secundários, já explicitada neste artigo. Maingueneau (2010) parte do postulado que os gêneros de discurso são realidades históricas e traz também a ideia de gênero irradiador, cuja capacidade é ativar a produção verbal de outros gêneros. Ele afirma:

em princípio, a categoria de 'gênero do discurso' (alguns preferem usar a expressão 'gênero textual') é baseada em critérios situacionais, tais como o papel dos participantes, o objetivo, o mídium, a organização textual, o tempo e o lugar etc. Gêneros são considerados dispositivos de comunicação sócio-historicamente condicionados, que estão sempre mudando e aos quais podem ser facilmente aplicadas metáforas como 'contrato', 'ritual' e 'jogo'. (MAINGUENEAU, 2010, p. 130)

Fica evidente diante das abordagens desses autores que o gênero de discurso diz respeito aos vários tipos de enunciados, produzidos em sociedade, com determinados fins comunicacionais, que se constituem com determinado estilo, para abordar determinados temas, com estrutura composicional relativamente estável. De uma maneira simplificada, podemos compreender gêneros de discurso como "entidades que funcionam em nossa vida cotidiana ou pública, para nos comunicar e para interagir com as outras pessoas" (ROJO \& BARBOSA, 2015, p. 16).

Quanto à multimodalidade, recorremos a Dionísio e Vasconcelos (2013, p 19). Segundo as autoras, "a sociedade na qual estamos inseridos se constitui como um grande ambiente multimodal, no qual palavras, imagens, sons, músicas, aromas, movimentos variados, texturas, formas diversas se combinam e estruturam um grande 
mosaico multissemiótico", o que ratifica a ideia de que a multimodalidade é um traço constituinte do sujeito e do mundo em que ele está inserido.

Pensar a interação humana é pensar a linguagem, uma vez que o sujeitos interagem por meio dela. Referimo-nos à linguagem em seu sentido amplo, ou seja, o verbal e o não-verbal. Exige-se, portanto, uma nova forma de conceber o texto. De acordo com Rojo (2012), as novas práticas sociais demandam leitores mais críticos, capazes de ler e construir sentido aos textos que se tornam cada vez mais multissemióticos. Diante desse contexto, trabalho com o livro didático no processo de ensino-aprendizagem corrobora para a formação desse leitor, uma vez que apresenta textos nos mais variados gêneros, permeados pela multimodalidade,. Esse fenômeno evidencia que os recursos multimodais correspondem a uma conexão entre o histórico, político, social, tanto do contexto de produção, quanto ao de circulação e de recepção desses textos.

\section{A multimodalidade no livro didático de língua portuguesa}

Diante dos aspectos da fundamentação teórica trazidos na seção anterior, entendemos, neste trabalho, o livro didático de língua portuguesa como um enunciado em um gênero de discurso. Temos consciência de que tal entendimento não é pacífico e que há quem refute essa ideia e o considere um suporte de diversos gêneros. Entretanto, retomaremos o assunto mais a frente, quando esclareceremos a concepção que temos de suporte.

Ao pensarmos na constituição do livro didático de língua portuguesa, partimos do ponto de vista de que ele é um enunciado essencialmente multimodal ${ }^{2}$, constituído de uma diversidade de textos e gêneros, mas que há uma escolha desses textos de acordo com a formação ideológica dos enunciadores, que irão compor sua estrutura por parte dos autores. Nessa escolha, entra em foco a relação social entre as editoras, a escola e a sociedade. Quando pensamos na constituição do livro que conhecemos hoje, vemos uma evolução histórica, como apontam Rojo e Barbosa (2015):

O livro didático é um gênero, por exemplo que passou por uma série de transformações ao longo do tempo histórico. Para além da Carta do $A B C$ e da Tabuada, nas décadas de 1950 e 1960, estudávamos em compêndios de gramática e em antologias, e os professores davam a aula. A maior parte desses gêneros (com exceção talvez do compêndio de gramática) desapareceu das escolas porque a esfera/campo escolar mudou. Foi justamente a junção desses três gêneros (manual de gramática, antologia e aula) que deu origem ao que hoje conhecemos por livro didático. (ROJO \& BARBOSA, 2015, p. 69)

Evidencia-se a relação do gênero com a esfera/campo a que pertence. Bakhtin (2011) expõe que essas esferas não são estáticas, à medida que estão em constante transformação com as mudanças históricas, sociais, culturais e, ao passarem por essas mudanças, muitos gêneros de discurso surgem e alguns se transformam de tal maneira que desaparecem ou deixam de existir. Além disso, os diversos gêneros de discurso que compõem o livro didático, ao fazerem parte de sua estrutura, deixam de exercer a

\footnotetext{
${ }^{2}$ Como texto multimodal, entendemos aqueles que são constituídos por mais de um tipo de linguagem (verbal, visual, gestual etc.).
} 
função primária que tinham ao serem constituídos, passando a ter uma função pedagógica ou de ensino, uma vez que não estão mais circulando na esfera de atividades em que foram constituídos, passando a compor uma outra esfera, que tem por objetivo o ensino.

Uma reportagem, por exemplo, ao ser incluída no livro didático de língua portuguesa, não mais exerce a função de noticiar ou informar a respeito de determinado assunto, mas passa a exercer a função de ensino a respeito da estrutura desse gênero, de como é constituída uma reportagem. Sua finalidade, como dos outros gêneros que compõem a estrutura do livro didático, é transformada, à medida que não possuímos no livro didático notícias atualizadas diariamente; da mesma maneira, uma pessoa que busca se informar a respeito dos acontecimentos mundiais não irá procurar o livro para esse fim, mas sim um jornal ou sites na internet.

De maneira semelhante, se pensarmos em outros gêneros de discurso que compõem o livro didático de língua portuguesa, chegaremos à mesma conclusão. Uma história em quadrinhos, por exemplo, ao ser incluída em um livro didático, deixa de ter sua finalidade inicial e passa a ser utilizada como objeto de ensino, seja para o trabalho com a interpretação de textos, com a leitura multimodal ou, muitas vezes, o trabalho de conteúdos gramaticais. Um leitor de histórias em quadrinhos não irá procurar um livro didático para ler tiras, charges ou cartoons, mas sim um gibi, um livro específico de HQ nas bancas ou livrarias. De acordo com Buzen,

quando os autores de livros didáticos de Língua Portuguesa, juntamente com outros agentes envolvidos no processo de edição, selecionam/negociam determinados objetos de ensino e elaboram unidades didáticas para ensinar tais objetos, eles estão, no nosso entender, produzindo um enunciado em um gênero do discurso, no sentido bakhtiniano do termo, cuja função social é re(a)presentar para cada geração de professores e estudantes o que é oficialmente reconhecido, autorizado como forma de conhecimento sobre a língua(gem) e sobre as formas de ensino-aprendizagem. (BUNZEN, 2005, p. 26)

Rojo e Barbosa (2015, p. 31) apresentam a ideia de gêneros intercalados, cuja origem está em Bakhtin. Segundo as autoras, são "gêneros integrados para compor enunciados em outros gêneros, como os diálogos e as cartas no romance, mas que mantém fronteiras nítidas em relação aos gêneros mais complexos que integram por meio de marcas explícitas de fronteiras". A composição do livro didático de língua portuguesa caracteriza-o como um gênero de discurso composto por diversos gêneros intercalados, que o constituem e passam a exercer, dentro de seu contexto, ou seja, no contexto de ensino-aprendizagem, a função pedagógica ou de ensino.

As condições de produção do livro, dentro da esfera didática ou de ensino, delimitam o conteúdo temático que ele deve abordar, de acordo com a série, a fim de atender a certos objetivos; o livro trata de temas específicos em cada série, todos voltados para o ensino de uma determinada unidade curricular. Cabe enfatizar, no entanto, que o tema vai além do assunto ou conteúdo que um texto se dispõe a abordar. O tema, na perspectiva dada por Bakhtin, é o "conteúdo inferido, com base na apreciação de valor, na avaliação, no acento valorativo que o locutor (falante ou autor) lhe dá" (ROJO \& BARBOSA, 2015, p. 87). O sentido do texto é construído a partir de um dado texto, pelo qual irá circular a formação discursiva do enunciador.

O estilo também fica evidente, se pensarmos que ele é caracterizado pelas escolhas de linguagem(ns) que é/são feita(s), a fim de construir o entendimento que se 
pretende. Os livros didáticos são constituídos pela multimodalidade, uma vez que apresentam essa simbiose de linguagens, como exemplifica a figura a seguir:

Figura 1

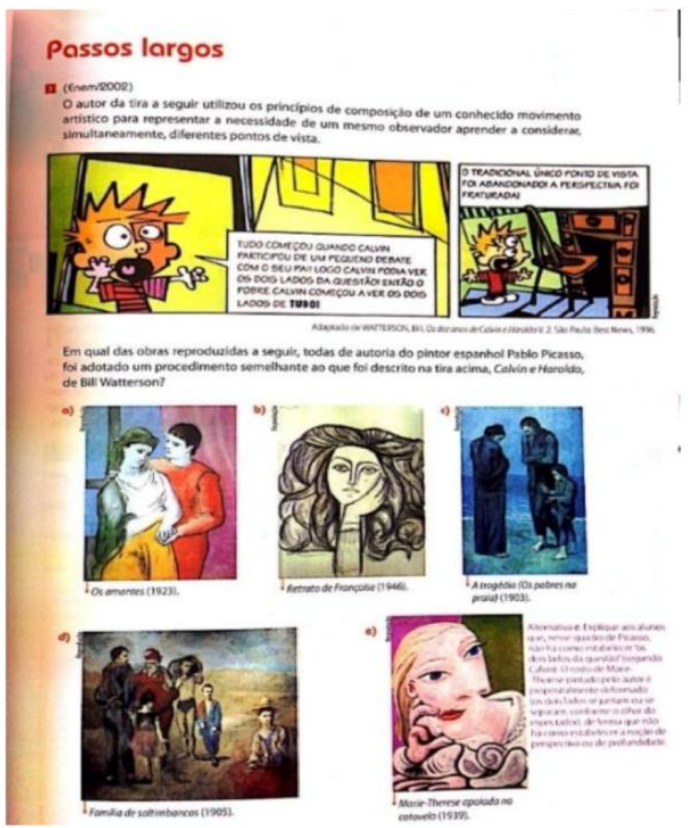

Fonte: SETTE, Maria das Graças Leão; TRAVALHA, Márcia; STARLING, Rozário. Português: linguagens em conexão. Vol. 3. São Paulo: Leya, 2013.

A página retirada de um livro didático de língua portuguesa do ensino médio apresenta tanto linguagem verbal (escrita de palavras) quanto a não-verbal (representada pelas figuras - uma tira cômica e algumas pinturas de autores; observam-se, ainda, outros elementos, como o tipo de letra, a distribuição do texto na página etc.). Percebese a presença de uma simbiose de linguagens, além de o enunciador escolher a distribuição das imagens, das palavras, cores, fontes diferentes - que também caracterizam a multimodalidade, como afirmamos. É importante que, ao trabalhar em sala de aula essa página - o professor evidencie esses aspectos multimodais, a fim de levar o aluno ao desenvolvimento da competência leitora, por exemplo. O formato da composição do livro didático é claro e específico; encontramos textos, teorias, exercícios, que estão sempre organizados por unidades e capítulos que abordam e reúnem assuntos específicos. A multimodalidade já se caracteriza na capa das diversas coleções de livros didáticos de língua portuguesa, como exemplifica a figura 2 , que traz a capa de duas coleções:

Figura 2: Capas de livros didáticos

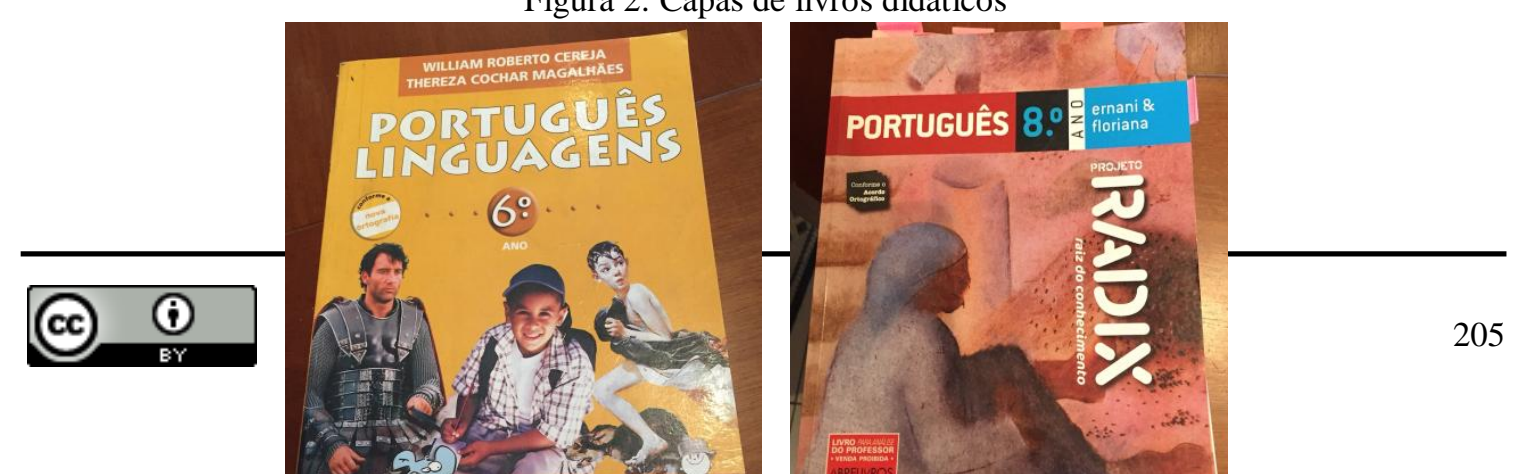


Fonte: Português linguagens (Cereja e Magalhães, 2016, p. 16) e Português - Projeto Radix (Ernani e Floriana, 2016, p.22), respectivamente

As duas capas trazem os aspectos multimodais, não só pelo uso de linguagem verbal e não-verbal, como também pelo uso de diferentes formatos da língua escrita (fontes e cores diferentes) e a própria distribuição na página. Observa-se que o recurso da multimodalidade é uma forma de fazer com que a coleção fique mais atrativa para o leitor, pressupondo haver uma maior interação entre os sujeitos que participam do processo de ensino-aprendizagem e o livro didático.

Ao falarmos sobre os gêneros de discurso, podemos remeter nossas considerações, ainda, à multimodalidade, como já elucidamos neste artigo. Segundo Maingueneau (2016), a comunicação é multimodal, isto é, mobiliza simultaneamente diversos canais. A comunicação verbal, por exemplo, segundo o autor, é um todo expressivo que associa gestos e signos linguísticos, o que incita os pesquisadores a proporem modelos e produção de linguagem em que cognição verbal e cognição espacial trabalhem juntas. Os elementos multimodais constituem-se em caracterizadores de efeitos de sentido, uma vez que a produção, a circulação e a recepção deles levam os coenunciadores a construírem sentidos para o enunciado.

Nessa perspectiva, para Maingueneau (2016), o crescimento de enunciados escritos comportam elementos icônicos, que crescem sem cessar, o que afeta a própria noção de texto, tanto que se fala em iconotexto para designar as produções semânticas em que imagem e linguagem verbal são indissociáveis. A importância da dimensão icônica se traduz em dois níveis (Maingueneau, 2015): de um lado, os enunciados verbais se incrustam nas imagens ou as imagens acompanham os textos; por outro, o próprio conjunto que as imagens e os enunciados verbais formam constitui também uma forma trabalhada em si mesma. Esse aspecto multimodal pode ser representado nas duas imagens retiradas de dois livros didáticos de língua portuguesa do ensino fundamental II:

Figura 3

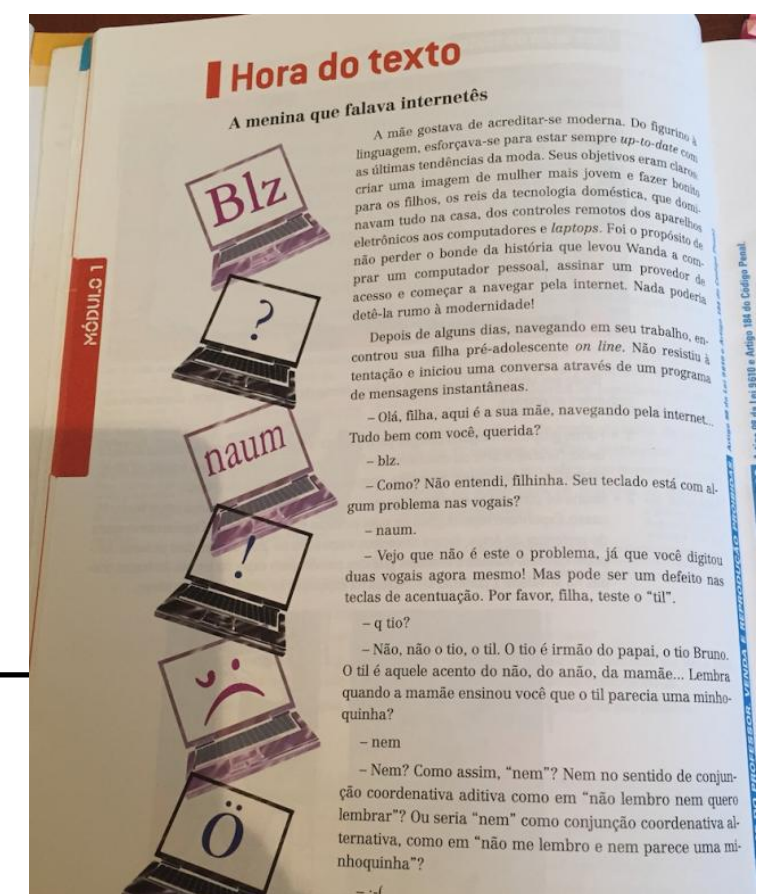




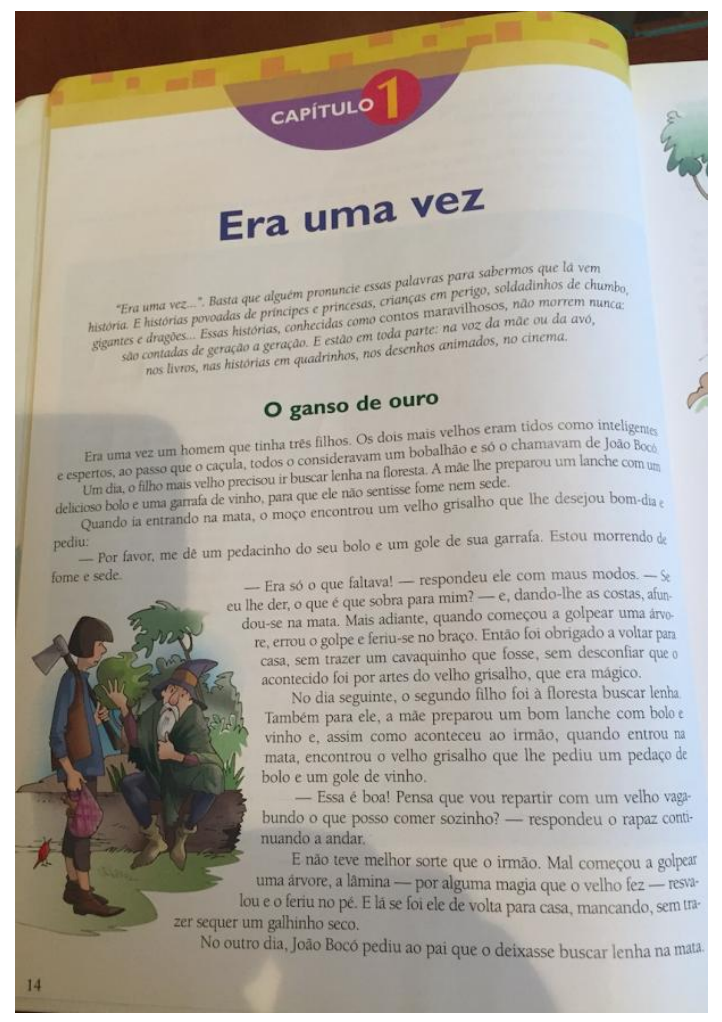

Fonte: Português linguagens (Cereja e Magalhães, 2016, p. 16) e Português - Projeto

Radix (Ernani e Floriana, 2016, p.22), respectivamente

É possível observar que, tanto na primeira imagem quanto na segunda, há uma relação entre o verbal e o não-verbal, sempre correlacionadas. Em "Era uma vez", temos o texto introdutório do capítulo do livro didático, em que há uma narrativa, marcada pelo gênero de discurso conto. A imagem das personagens na parte esquerda inferior da página está diretamente relacionada com a história contada. Embora não seja totalmente explicitado nas figuras, cada capítulo do livro didático de uma unidade possui uma identificação: uma margem em amarelo e marrom, o número do capítulo em amarelo, dentro de um círculo vermelho, que por sua vez está dentro de uma meia bola roxa. Esse padrão é mantido em todos os capítulos, variando a cor da unidade do livro. Podemos dizer que esta é uma organização do texto para que o aluno reconheça o início do capítulo, diferenciando de outras partes que constituem o gênero de discurso livro didático de língua portuguesa. No caso deste capítulo, foi escolhida a cor roxa e o número 1 em vermelho.

$\mathrm{Na}$ segunda imagem, o livro didático nos apresenta um texto com sequências narrativas; o conteúdo do texto está relacionado com as imagens que permeiam toda a margem esquerda do texto. Além desses recursos, cabe ressaltar outros caracterizadores multimodais: as cores, o uso de diferentes letras e, como afirmamos, a própria distribuição do texto na página, que produzem efeitos de sentido no destinatário, no caso os alunos que usam o livro didático no processo de ensino-aprendizagem de língua portuguesa.

A análise apresentada dos livros didáticos de língua portuguesa vai ao encontro do que afirma Bakhtin:

uma determinada função (científica, técnica, publicística, oficial, cotidiana) e determinadas condições de comunicação discursiva, específicas de cada campo, geram determinados gêneros, isto é, determinados tipos de enunciados estilísticos, temáticos e composicionais relativamente estáveis. (BAKHTIN, 2011, p. 266)

Concordamos que o livro didático de língua portuguesa se configura como um gênero de discurso "não pelo viés estático do produto, mas pelo viés dinâmico da produção" (BUNZEN, 2005, p. 38) e que

estudar o LDP como um gênero do discurso implica justamente procurar entendê-lo como um produto sócio-histórico e cultural em que atuam vários agentes (autores, editores, revisores, leitores críticos, professores, etc.), com certas relações sociais entre si, na produção e seleção de enunciados concretos com determinadas finalidades. (BUNZEN, 2005, p. 37) 
Conforme dissemos anteriormente, há divergências nesse entendimento. Marcuschi (2003) afirma que o livro didático é nitidamente um suporte textual. O autor expõe que todo gênero tem um suporte, mas a distinção entre ambos nem sempre é simples. Bunzen (2005) esclarece que a chave de tal de divergência parece ser como classificar ou compreender o processo de junção de vários textos em gêneros diversos na composição do livro didático. $\mathrm{O}$ autor mostra que

para Marcuschi (2003: 13), 'Bakhtin nunca teria classificado o livro didático entre os gêneros secundários e sim como um conjunto de gêneros'. O LDP, se entendido como suporte, não mudaria a identidade desses gêneros, segundo o autor, visto que não há reversibilidade de forma, embora eles sofram uma reversibilidade de função, pois assumem uma funcionalidade didática. (BUNZEN, 2005, p. 33)

A análise apresentada neste artigo pactua com as ideias de Bunzen, quando questiona se realmente não há uma reversibilidade de forma e função nos gêneros que irão compor o livro didático. Entendemos que a intercalação desses variados gêneros de discurso faz parte do processo de constituição de um outro gênero, sobretudo pela sua forma de produção intertextual, que reflete uma escolha não ao acaso, mas de acordo com a formação discursiva do enunciador. Tomamos a posição de não criar entre gênero e suporte uma dicotomia. E, para tanto, buscamos o entendimento do termo suporte. Apesar do termo ter se tornado muito recorrente, sobretudo mediante o avanço das novas tecnologias, ainda não há uma definição clara e objetiva a respeito de suporte. Bonini (2011) há algum tempo já avança nessa discussão e expõe os seguintes entendimentos:

a) gênero - unidade da interação linguageira que se caracteriza por uma organização composicional, um modo característico de recepção e um modo característico de produção. Pode ser de natureza verbal, imagética, gestual, etc. Como unidade, equivale ao enunciado bakhtiniano; b) mídia - tecnologia de mediação da interação linguageira e, portanto, do gênero como unidade dessa interação. Cada mídia, como tecnologia de mediação, pode ser identificada pelo modo como caracteristicamente é organizada, produzida e recebida e pelos suportes que a constituem; e c) suporte - elemento material (de registro, armazenamento e transmissão de informação) que intervém na concretização dos três aspectos caracterizadores de uma mídia (suas formas de organização, produção e recepção). (BONINI, 2011 , p. 688 - grifos nossos)

Entendemos como suporte o elemento material, um objeto em que determinado gênero está vinculado. Ao pensarmos no livro didático de língua portuguesa pela dinâmica de sua produção, não poderíamos restringi-lo a um simples elemento material de circulação de diversos gêneros. Ao analisarmos o livro didático de língua portuguesa que já possui suas primeiras versões digitais, parece-nos claro o entendimento de que ele se caracteriza como um enunciado em um gênero de discurso que circula em diferentes suportes, como o impresso (em papel) e o digital (em um programa ou aplicativo de computador).

\section{Palavras finais}


O presente artigo teve como objetivo analisar o livro didático de língua portuguesa, a fim de comprovar nossa hipótese de que ele se configura como um enunciado em um gênero de discurso. Para isso, realizamos um levantamento bibliográfico a respeito do conceito de gênero discursivo, buscando compreender de que maneira um gênero se estrutura e se constitui.

A partir dos conceitos trabalhados por Bakhtin (2011) e Maingueneau (2006, 2010 e 2016), definimos gênero de discurso e procuramos analisar a forma de constituição do livro didático. Articulamos as ideias expostas por Rojo e Barbosa (2015) e Bunzen (2005) e chegamos à conclusão de que para nós o livro didático de língua portuguesa se constitui em um gênero de discurso composto por diversos gêneros intercalados, que o constituem e passam a exercer, dentro de seu contexto, a função de ensino. Apresentamos um contraponto com o conceito de suporte, mostrando que para nós o livro didático é considerado como um gênero de discurso, que pode circular em diferentes suportes, como o impresso (em papel) e o digital (em um programa ou aplicativo de computador).

O trabalho com a multimodalidade no processo de ensino-aprendizagem de língua portuguesa, mediado pelo livro didático, abre uma perspectiva para a formação de um leitor crítico, capaz de construir sentidos para os enunciados que constituem o gênero de discurso presente no livro didático - considerado por nós como um gênero de discurso multifacetado. A partir do momento que é feito esse trabalho com a leitura, o aluno passa a desenvolver a competência leitora, não só do verbal, mas também do não verbal, além de outros elementos constituintes da multimodalidade, como apontados neste artigo.

\section{Referências}

BAKHTIN, Mikhail. Os gêneros do discurso. In: Estética da criação verbal. 6 ed. São Paulo: WMF Martins Fontes, 2011. p. 261-306.

BONINI, Adair. Mídia/suporte e hipergênero: os gêneros textuais e suas relações. Belo Horizonte: RBLA, 2011. v. 11, n. 3, p. 679-704.

BUNZEN, Clécio. Livro didático de língua portuguesa: um gênero do discurso. 2005. 168 f. Dissertação (Mestrado em Letras) - Instituto de Estudos da Linguagem. Campinas, SP., 2005.

BUNZEN, Clecio; MENDONÇA, Márcia (orgs.). Múltiplas linguagens para o ensino médio. São Paulo: Parábola Editorial, 2013.

CEREJA, William Roberto e MAGALHÃES, Thereza Cochar. Português linguagens. 6. ano. São Paulo: Atual Editora, 2016.

DIONÍSIO, Angela Paiva e VASCONCELOS, Leila Janot. "Multimodalidade, gênero textual e leitor" in BUNZEN, Clécio e MENDONÇA, Márcia (orgs.). Múltiplas linguagens para o ensino médio. São Paulo: Parábola, 2013, p. 19-42.

MAINGUENEAU, Dominique. Discurso e Análise de discurso. São Paulo: Parábola, 2016. 
Doze conceitos em análise do discurso. São Paulo: Parábola Editorial, 2010. $229-246$.

. O quadro genérico. In: $O$ discurso literário. São Paulo: Contexto, 2006. p.

MARCUSCHI, Luiz Antônio. “A questão do suporte dos gêneros textuais”. (mimeo), 2003.

ROJO, Roxane; BARBOSA, Jacqueline. Hipermodernidade, multiletramentos $e$ gêneros discursivos. São Paulo: Parábola Editorial, 2015.

TERRA, Ernani e CAVAlLETE, Florinda Toscano. Português - Projeto Radix - 8. ano. São Paulo: Ática, 2016.

Recebido em 19 de maio de 2019

Aceito em 26 de setembro de 2019 